Research Article

\title{
Acoustic Emission and Damage Characteristics of Granite Subjected to High Temperature
}

\author{
X. L. Xu (iD) ${ }^{1,2}$ and Z.-Z. Zhang ${ }^{2}$ \\ ${ }^{1}$ School of Architecture and Civil Engineering, Nantong University, Nantong 226019, China \\ ${ }^{2}$ State Key Laboratory for Geomechanics and Deep Underground Engineering, China University of Mining and Technology, \\ Xuzhou 221008, China \\ Correspondence should be addressed to X. L. Xu; xuxiaoli@ntu.edu.cn
}

Received 31 August 2017; Revised 27 November 2017; Accepted 4 December 2017; Published 13 February 2018

Academic Editor: Carlo Santulli

Copyright (C) 2018 X. L. Xu and Z.-Z. Zhang. This is an open access article distributed under the Creative Commons Attribution License, which permits unrestricted use, distribution, and reproduction in any medium, provided the original work is properly cited.

\begin{abstract}
Acoustic emission (AE) signals can be detected from rocks under the effect of temperature and loading, which can be used to reflect rock damage evolution process and predict rock fracture. In this paper, uniaxial compression tests of granite at high temperatures from $25^{\circ} \mathrm{C}$ to $1000^{\circ} \mathrm{C}$ were carried out, and $\mathrm{AE}$ signals were monitored simultaneously. The results indicated that AE ring count rate shows the law of "interval burst" and "relatively calm," which can be explained from the energy point of view. From $25^{\circ} \mathrm{C}$ to $1000^{\circ} \mathrm{C}$, the rock failure mode changes from single splitting failure to multisplitting failure, and then to incomplete shear failure, ideal shear failure, and double shear failure, until complete integral failure. Thermal damage $\left(D_{T}\right)$ defined by the elastic modulus shows logistic increase with the rise of temperature. Mechanical damage $\left(D_{M}\right)$ derived by the AE ring count rate can be divided into initial stage, stable stage, accelerated stage, and destructive stage. Total damage $(D)$ increases with the rise of strain, which is corresponding to the stress-strain curve at various temperatures. Using AE data, we can further analyze the mechanism of deformation and fracture of rock, which helps to gather useful data for predicting rock stability at high temperatures.
\end{abstract}

\section{Introduction}

The characteristics of rock strength and deformation will be affected by high temperature [1-9]. Many rock engineerings, such as nuclear waste disposal [10], geothermal resource development [11, 12], underground engineering stability [13], postdisaster reconstruction [14, 15], and other projects, are inevitably related to high temperature. The related mechanical parameters are the basis for the study of excavation and stability in underground engineerings.

The peak strength is the macroscopic representation of rock, which cannot reflect internal damage evolution. As an important method in acoustic nondestructive testing, rock internal defects and damage evolution process can be accurately monitored by acoustic emission (AE) detection [16-19].

In recent years, $\mathrm{AE}$ detection technology has been used in rock mechanics by many scholars [20-27]. For example,
Ganne et al. [20] studied the brittleness of rock before peak stress by the AE technique, and four stages of accumulated $\mathrm{AE}$ energy were given. Alkan et al. [21] determined the expansion boundaries of rock by studying AE signals of different strain stages in triaxial compression tests. He et al. [22] observed that there were much higher amplitude and lower frequency events near the bursting failure of rock samples, and the accumulated AE energy release increased rapidly from unloading state to rock failure. Gasc et al. [23] studied rock structural transformation and mineral reaction under high temperatures and high pressures by X-ray diffraction and $\mathrm{AE}$ detection of serpentine. Chmel et al. [24] studied AE energy release of granite under impact loading. Zhang et al. [25] studied AE properties of halite, glauberite, and gypsum during compression test with different loading styles and saturation conditions. Zhang et al. [26] calculated the correlation fractal dimensions of $\mathrm{AE}$ counts at different 
stress levels, and the value at the failure point showed a polynomial decline with the increase of temperature. Guo et al. [27] carried out comprehensive studies on rockdetected $\mathrm{AE}$ characteristics, failure mode, crack initiation stress, damage evolution law, and stress-strain constitutive model after thermal damage.

Since AE monitoring technology has practical application in the determination of ground stress, tunnel, and slope engineerings $[28,29]$, there are few studies on $\mathrm{AE}$ characteristics of granite at high temperature. Granite, as an ideal material for storing high radioactive nuclear waste, has a series of advantages such as low permeability, compactness, and high strength. Therefore, it is of theoretical and practical value to study $\mathrm{AE}$ and damage characteristics of granite at high temperatures.

In this paper, uniaxial compression tests of granite at different temperatures $\left(25^{\circ} \mathrm{C}, 200^{\circ} \mathrm{C}, 400^{\circ} \mathrm{C}, 600^{\circ} \mathrm{C}, 800^{\circ} \mathrm{C}\right.$, and $1000^{\circ} \mathrm{C}$ ) are carried out, and $\mathrm{AE}$ signals in the deformation and failure process are monitored simultaneously. Rock mechanical properties, AE characteristics, failure modes, and damage evolution laws are analyzed. The results can provide useful references to predict rock failure at high temperatures.

\section{Experimental Methodology}

Granite was chosen from Shandong province of China, which is mainly comprised of feldspar, quartz, mica, and so on, based on X-ray diffraction analysis (Figure 1). Due to the internal volume limit of the high temperature environment furnace, according to the International Society of Rock Mechanics (ISRM) standard [30], $25 \mathrm{~mm}$ diameter rock specimens with the height-to-diameter ratio of 2 were used in the test. The average density of granite is $2.612 \mathrm{~g} / \mathrm{cm}^{3}$ at room temperature.

2.1. Test Equipment. The test was completed in the State Key Laboratory for Geomechanics and Deep Underground Engineering, China University of Mining and Technology. The main equipment used in this test includes a MTS810 material testing system (Figure 2(a)), a MTS652.02 high temperature environment furnace matched with MTS810 (Figure 2(b)), and the PCI-2 all-digital AE monitoring system of American Physical Acoustics Corporation (experimental system) (Figure 2(c)).

2.2. Test Procedure and Method. The process of whole test is divided into two parts. (1) Firstly, rock samples were heated to the preset temperatures of $200^{\circ} \mathrm{C}, 400^{\circ} \mathrm{C}, 600^{\circ} \mathrm{C}, 800^{\circ} \mathrm{C}$, and $1000^{\circ} \mathrm{C}$ at a heating rate of $50^{\circ} \mathrm{C} / \mathrm{min}$ in MTS 652.02 . The high temperature was kept for 20 minutes to ensure that the rock samples were heated evenly. There are three samples at each temperature point. (2) Secondly, the uniaxial compression test was carried out by MTS810 using displacement control, at the loading rate of $0.005 \mathrm{~mm} / \mathrm{s}$ at high temperatures. Considering the effect of reducing ambient noise and improving signal acquisition reliability, the $\mathrm{AE}$ threshold was set to $45 \mathrm{~dB}$ and the amplifier was

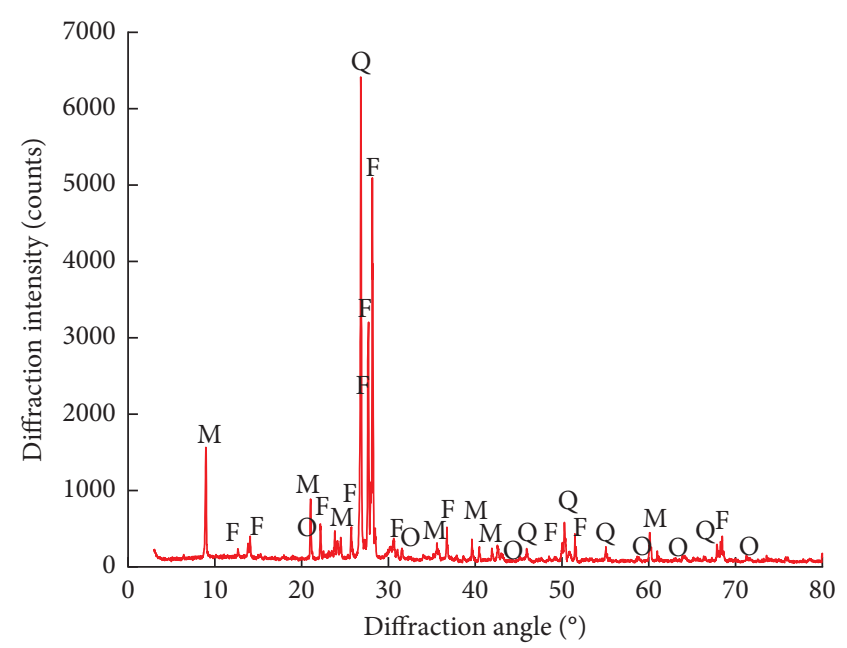

FIgURE 1: X-ray diffraction pattern of granite. M: mica; Q: quartz; F: feldspar; O: others.

set to $40 \mathrm{~dB}$. The operating frequency of the NANO-30 sensor is $100 \sim 400 \mathrm{kHz}$, the lower limit of the filter parameters was set to $100 \mathrm{kHz}$, the upper limit was set to $400 \mathrm{kHz}$, a total of 1024 data were collected in every incident event, and the acquisition rate was $1 \mathrm{MHz}$. At the beginning of the compression test, the AE signal was monitored and recorded at the same time.

\section{Test Results and Discussions}

3.1. Mechanical Properties. Typical stress-strain curves are selected under uniaxial compressive tests for each group of temperature, as shown in Figure 3. The stress-strain curves show similar shape in general and can be divided into four stages of compaction, elasticity, yield, and failure; this result is the same as that of most of the researches [1-7].

Since there are three rock samples at the same temperature, Figure 4 gives the average value of peak stress and peak strain with temperature (the phase transition line is at $573^{\circ} \mathrm{C}$, when the quartz changes from $\alpha$ phase to $\beta$ phase), and two kinds of curves can be divided into four stages.

(1) The first stage is from $25^{\circ} \mathrm{C}$ to $400^{\circ} \mathrm{C}$. At this stage, the adhesive water escapes from inside of the rock at about $100^{\circ} \mathrm{C}$, the strong combination water escapes out in the range of $200^{\circ} \mathrm{C}$ to $300^{\circ} \mathrm{C}$, and the crystallization water precipitates out of rock at about $400^{\circ} \mathrm{C}$. The loss of crystal water will lead to the destruction of mineral lattice skeleton, resulting in the decrease of rock strength from $79.44 \mathrm{MPa}$ of $20^{\circ} \mathrm{C}$ to $55.78 \mathrm{MPa}$ of $400^{\circ} \mathrm{C}$, decreased by $29.78 \%$. The peak strain decreases from $1.24 \%$ of $20^{\circ} \mathrm{C}$ to $0.98 \%$ of $400^{\circ} \mathrm{C}$, decreased by $20.66 \%$.

(2) The second stage is from $400^{\circ} \mathrm{C}$ to $600^{\circ} \mathrm{C}$. Mineral structure water precipitates from the internal of rock in the range of $400^{\circ} \mathrm{C}$ to $500^{\circ} \mathrm{C}$, and quartz changes from $\alpha$ phase to $\beta$ phase at $573^{\circ} \mathrm{C}$ [32], causing significant changes in rock mechanical properties. At this stage, rock strength decreases rapidly to 


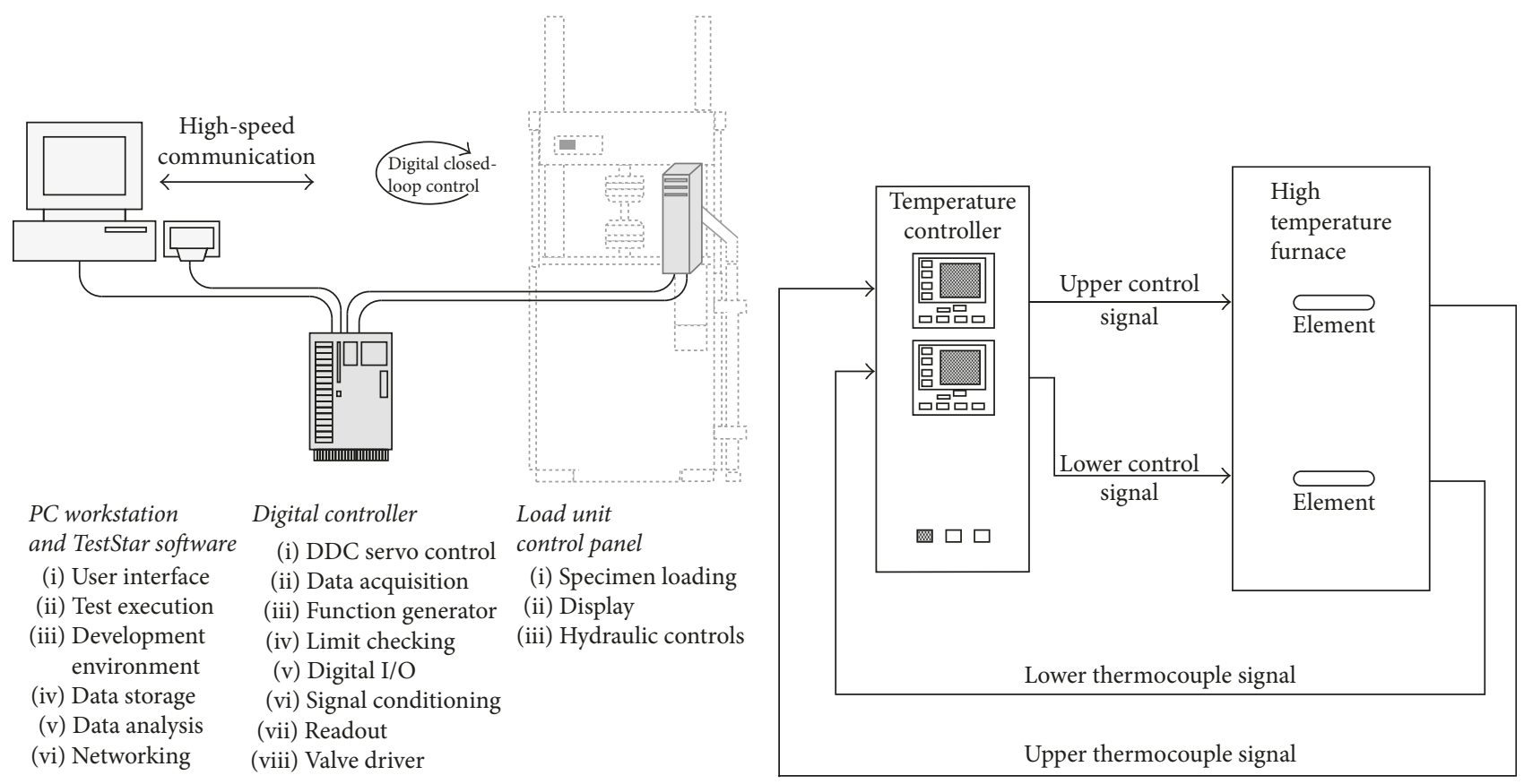

(a)

(b)

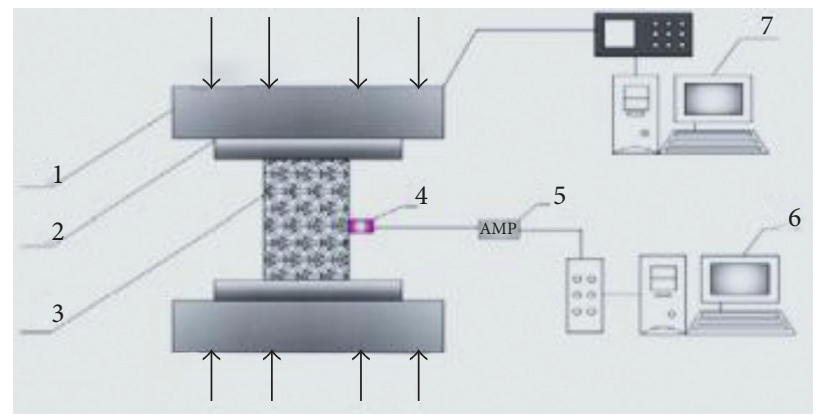

(c)

FIGURE 2: Schematic of the experimental system. (a) System diagram of MTS810. (b) Temperature controller/furnace block diagram of MTS652.02. (c) 1: compression testing machine; 2: insulation pads; 3: granite sample; 4: AE probe; 5: preamplifiers; 6: AE data acquisition and processing system; 7: load control system [31].

$30.16 \mathrm{MPa}$ of $600^{\circ} \mathrm{C}$, with a decline of $45.93 \% \mathrm{com}-$ pared to $400^{\circ} \mathrm{C}$. The peak strain increases from $0.98 \%$ of $400^{\circ} \mathrm{C}$ to $1.06 \%$ of $600^{\circ} \mathrm{C}$, with an increase of $8.16 \%$.

(3) The third stage is from $600^{\circ} \mathrm{C}$ to $800^{\circ} \mathrm{C}$. Al-O, K-O, $\mathrm{Na}-\mathrm{O}$, and $\mathrm{Ca}-\mathrm{O}$ in rock minerals are broken, and some minerals are melted, resulting in a large number of microscopic defects. Since the phase transition has already occurred in the second stage and rock strength has been fundamentally weakened, the peak stress has no obvious variation at this stage. However, the peak strain increases to $1.29 \%$ of $800^{\circ} \mathrm{C}$, increased $21.28 \%$ compared to $600^{\circ} \mathrm{C}$.

(4) The fourth stage is from $800^{\circ} \mathrm{C}$ to $1000^{\circ} \mathrm{C}$. Quartz changes from $\beta$ - to $\beta$-squamous quartz at $870^{\circ} \mathrm{C}$ [33], causing peak stress decreased to $24.82 \mathrm{MPa}$ at $1000^{\circ} \mathrm{C}, 21.51 \%$ compared to $800^{\circ} \mathrm{C}$. The peak strain increases rapidly to $1.99 \%$ of $1000^{\circ} \mathrm{C}$, with an increase of $54.11 \%$ compared to $800^{\circ} \mathrm{C}$. The rise of temperature causes the enhancement of rock molecules' thermal motion and leads to the weakness of rock cohesion, and then the grain surface is more likely to slip, and the plasticity is more obvious at high temperature.

3.2. AE Characteristics. AE signal is directly related to the evolution of rock damage. The internal cracks in the rock are evolved and damaged during uniaxial compression tests; the energy contained in the rock will be released in the form of elastic waves, and these weak signals can be monitored and recorded by $\mathrm{AE}$ sensors. So, the AE technology has become an important way to study rock damage mechanism and predict rock failure. According to the experimental data, the stress-strain curve, the $\mathrm{AE}$ ring count rate, and the accumulated AE ring counts subjected to the temperature of $25^{\circ} \mathrm{C}$ to $1200^{\circ} \mathrm{C}$ are shown in Figure 5 . 


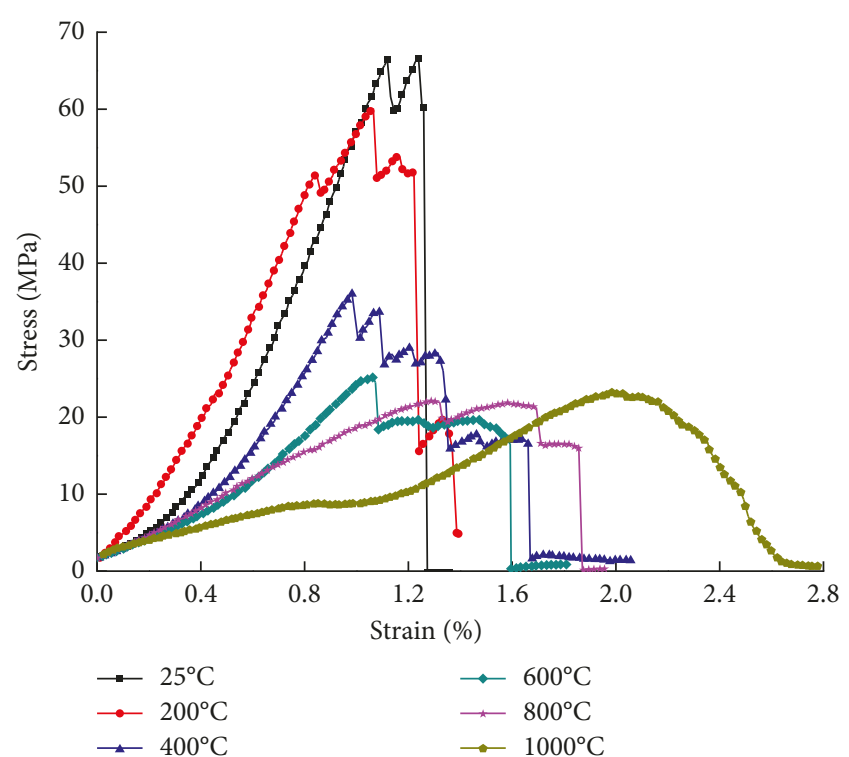

FIGURE 3: Stress-strain curves of granite under uniaxial compression at high temperatures.

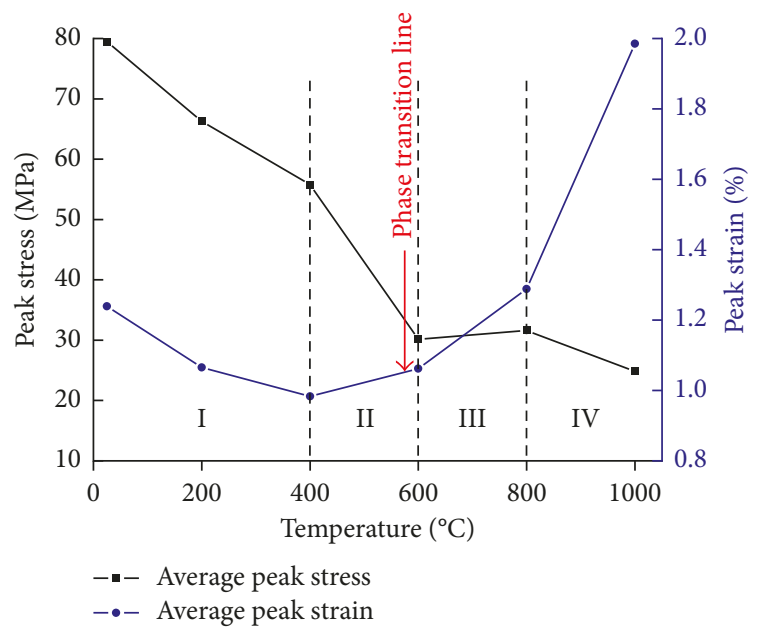

FIgURE 4: Average peak stress and peak strain with temperature.

It can be seen that the $\mathrm{AE}$ ring count rate is corresponding to rock stress-strain curves at various temperatures. Firstly, the AE signal is very small at the rock compaction stage and then increases slightly at elastic deformation stage due to the germination of microcracks. With the increase of loading, the AE signal increases obviously because of the expansion of rock internal cracks and reaches the maximum value at rock peak stress, and then it decreases gradually until the sample is completely damaged.

Figure 6 shows that the change of accumulated AE counts with temperature is consistent with the change of peak stress but the variation range is inconsistent. From $25^{\circ} \mathrm{C}$ to $600^{\circ} \mathrm{C}$, the accumulated $\mathrm{AE}$ counts decrease from $22.91 \times 10^{5}$ to $1.35 \times 10^{5}$, with a decrease of $94.10 \%$, and the peak stress decreases by $62.03 \%$. From $600^{\circ} \mathrm{C}$ to $800^{\circ} \mathrm{C}$, the accumulated $\mathrm{AE}$ counts increase rapidly and reach the maximum value of $25.34 \times 10^{5}$ of $800^{\circ} \mathrm{C}$, this may be due to a large number of microscopic cracks that extend to macroscopic cracks at high temperatures, and rock plasticity is significantly enhanced. There is no obvious variation in peak stress at this stage; the reason has been explained in Section 3.1. From $800^{\circ} \mathrm{C}$ to $1000^{\circ} \mathrm{C}$, the accumulated $\mathrm{AE}$ counts have a decline of $57.58 \%$ and peak stress decreases by $21.51 \%$ compared to $800^{\circ} \mathrm{C}$.

3.3. Failure Mode. Not only rock strength, but also the failure mode was affected by high temperature. Granite is composed of various mineral crystals, with regional, noncontinuous, heterogeneous, and other physical properties. After subjected to different high temperatures, the change of rock internal grain structure will lead to different failure modes.

Figure 7 shows different rock failure modes under uniaxial compression tests. From $25^{\circ} \mathrm{C}$ to $200^{\circ} \mathrm{C}$, rock failure transforms from single splitting surface to multisplitting surface, which is mainly caused by tensile cracks at this stage, and the failure surface is parallel to axial stress. At $400^{\circ} \mathrm{C}$, there is an incomplete penetrating shear crack after rock failure, rock surface is stripped, and the grain is loose. This is because rock failure is caused by the common role of tension and shear. When temperature reaches $573^{\circ} \mathrm{C}$, the rock sample undergoes phase transition, the cohesion between the particles becomes weak, and the shear crack propagates and converges. Therefore, there are more cracks and the rock shows the ideal shear failure type at $600^{\circ} \mathrm{C}$; then, the rock failure type changes from double shear rupture at $800^{\circ} \mathrm{C}$ to completely integral rupture at $1000^{\circ} \mathrm{C}$.

\section{Analysis of Damage Characteristics}

4.1. Mechanical Damage $\left(D_{M}\right)$ Caused by Loading. Since the evolution of rock microcracks under loading is a random process, the microintensity can be described using the Weibull statistical distribution, which is expressed as [34]

$$
\phi(\varepsilon)=\frac{m}{\alpha} \varepsilon^{m-1} \exp \left(\frac{-\varepsilon^{m}}{\alpha}\right),
$$

where $\phi(\varepsilon)$ is the probability of rock microscopic element damage $m$ and $\alpha$ are the Weibull distribution parameters. A large number of research results show that the accumulated $\mathrm{AE}$ ring count is corresponding to the slip of dislocations, the initiation of microscopic cracks, and the expansion of macroscopic cracks in rock materials. In essence, the $\mathrm{AE}$ activity is a statistical law, so it must be consistent with the statistical distribution of rock internal flaws. If the accumulated AE ring count is $\Omega_{m}$ when the rock specimen is completely damaged, then the accumulated AE ring count when the strain increased to $\varepsilon$ is

$$
\Omega=\Omega_{m} \int_{0}^{\varepsilon} \phi(x) d x .
$$

Substituting (1) into (2), we get

$$
\frac{\Omega}{\Omega_{m}}=1-\exp \left(\frac{-\varepsilon^{m}}{\alpha}\right) \text {. }
$$




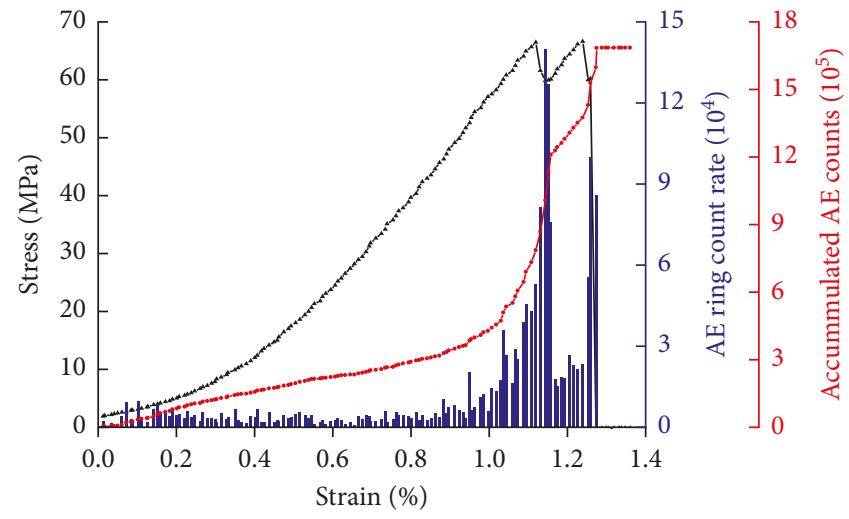

-1- Stress

- AE ring count rate -.- Accumulated AE counts

(a)

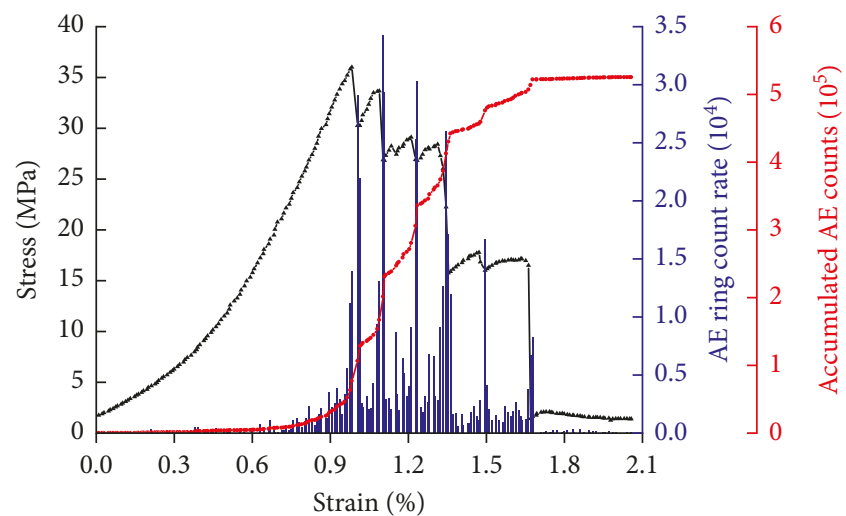

- $\mathbf{-}$ - Stress

AE ring count rate

-. Accumulated AE counts

(c)

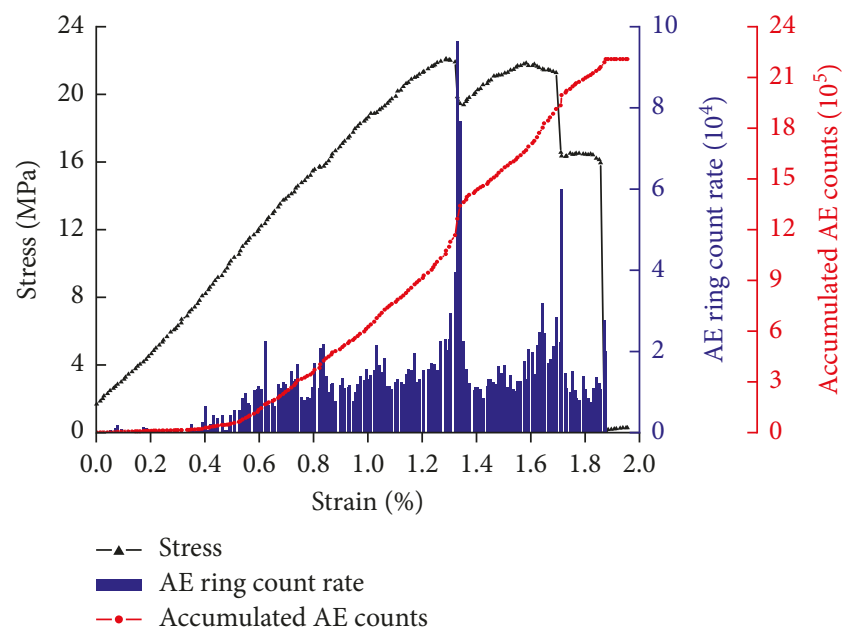

(e)

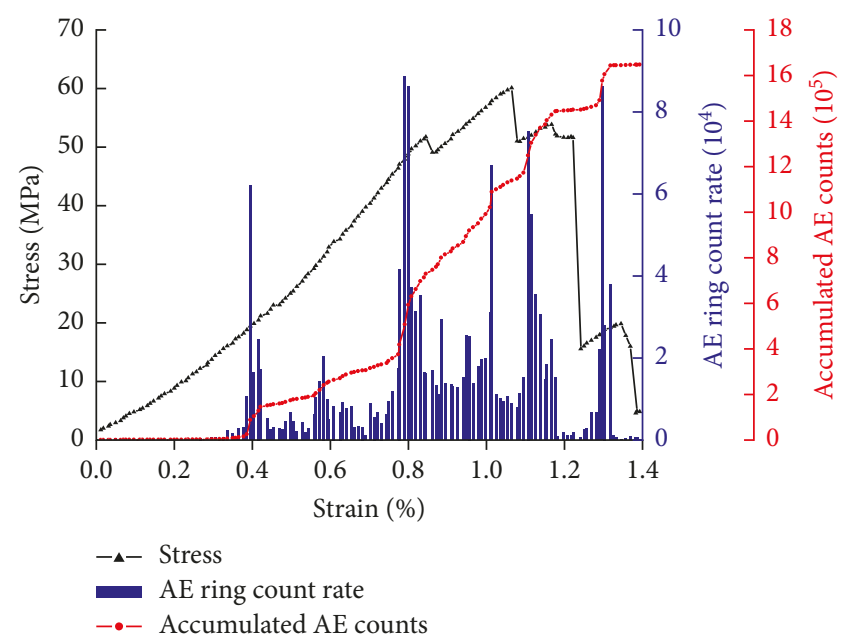

(b)

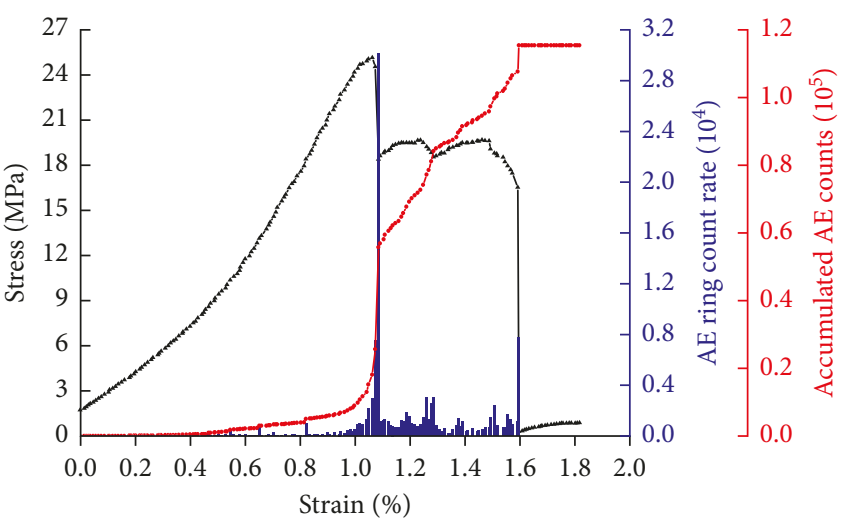

$-\mathbf{-}-$ Stress

- $\mathrm{AE}$ ring count rate

-•- Accumulated AE counts

(d)

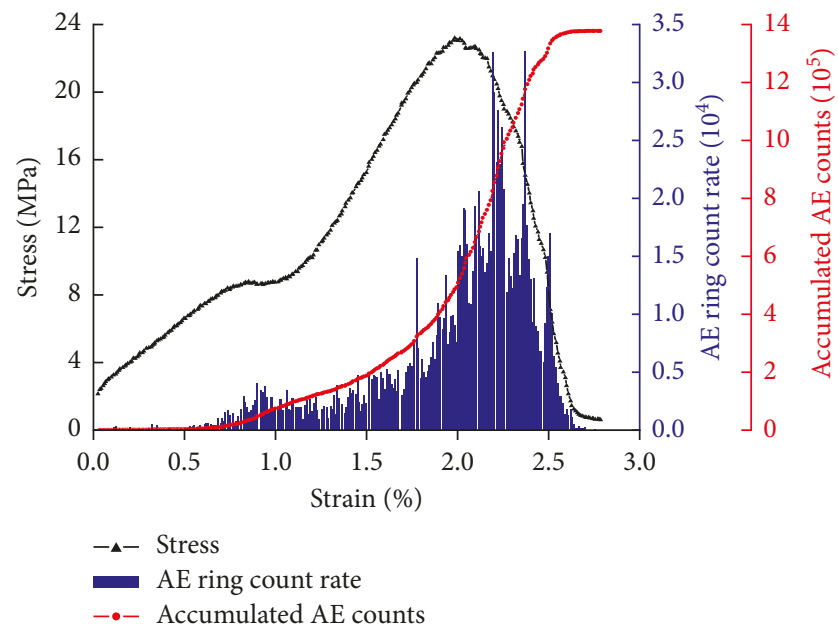

(f)

Figure 5: Stress-strain and AE curves of granite under uniaxial compression test at high temperatures. (a) $25^{\circ} \mathrm{C},(\mathrm{b}) 200^{\circ} \mathrm{C}$, (c) $400^{\circ} \mathrm{C},(\mathrm{d})$ $600^{\circ} \mathrm{C}$, (e) $800^{\circ} \mathrm{C}$, and (f) $1000^{\circ} \mathrm{C}$. 


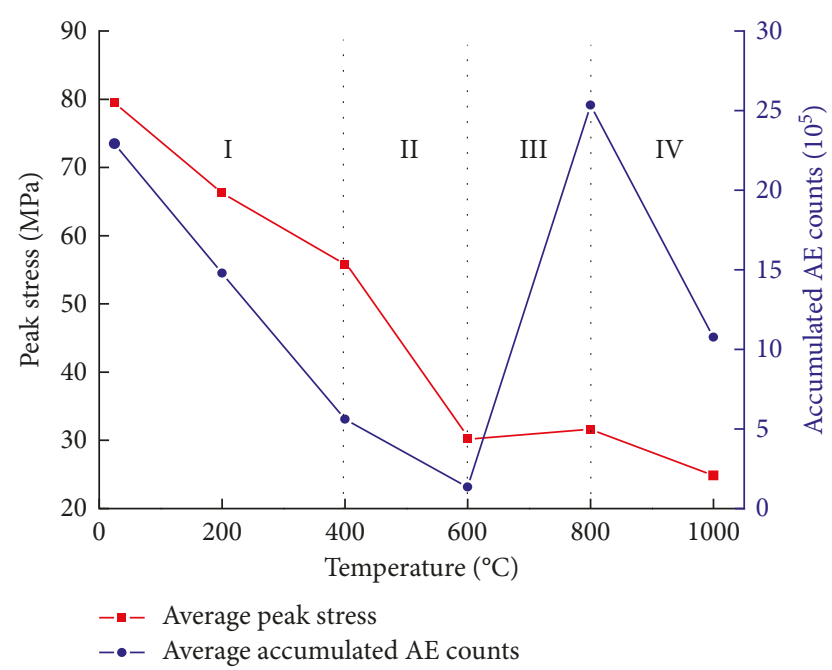

FIgURE 6: Average peak stress and accumulative AE counts with temperature.

The variable $D_{M}$ is the measurement of rock mechanical damage, which has a relationship with $\phi(x)$ :

$$
D_{M}=\int_{0}^{\varepsilon} \phi(x) d x=1-\exp \left(\frac{-\varepsilon^{m}}{\alpha}\right) \text {. }
$$

Comparing (3) and (4), $D_{M}$ can be expressed as

$$
D_{M}=\frac{\Omega}{\Omega_{m}} .
$$

According to (5), the rock mechanical damage evolution curve under uniaxial compression test at room temperature is shown in Figure 8.

The process of rock mechanical damage under uniaxial compression can be divided into four stages. (1) Initial damage stage I. $D_{M}$ is very small. At this stage, the rock sample is in the microcrack enclosed phase and the initial microcracks and fissures do not start to expand and the $\mathrm{AE}$ ring count is few. (2) Stable development stage II. $D_{M}$ increases steadily with the increase of strain. The rock crack begins to expand, releasing stable AE signals, which corresponds to the elastic phase of stress-strain curve. (3) Accelerated development stage III. $D_{M}$ increases dramatically. The original and new cracks are continuously expanding and merging through the rock, and finally forming macroscopic cracks. The release of elastic strain energy increases dramatically, manifesting as unusually active AE activities, which corresponds to rock unsteady expansion. (4) Destructive stage IV. $D_{M}$ in this stage tends to be gentle and gradually increases to 1 with the increase of strain. The formation of main rupture surface causes a sudden release of stress, resulting in a rapid decline in rock strength. It can be seen that $D_{M}$ defined by the accumulated $\mathrm{AE}$ ring counts can well reflect the whole progressive failure of the rock.

Figure 9 shows that the rock mechanical damage evolution slows down as the temperature increases, indicating that temperature has already caused thermal damage in rock samples.

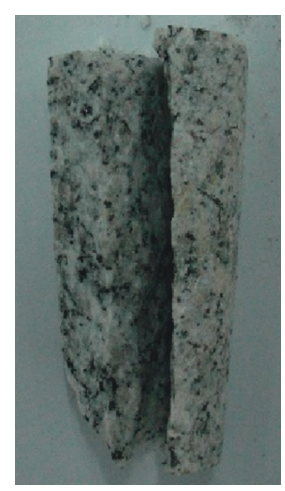

(a)

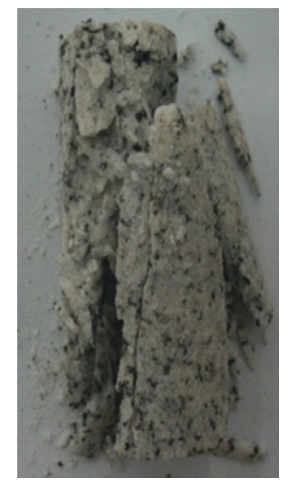

(c)

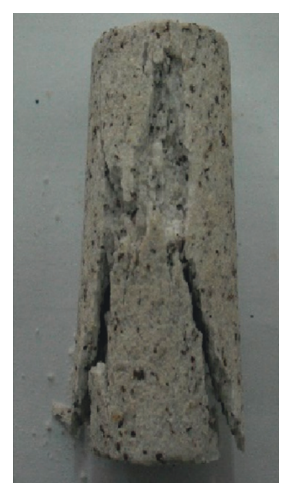

(e)

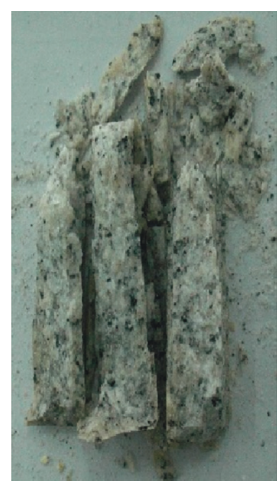

(b)

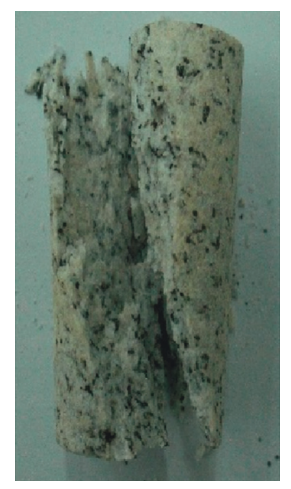

(d)

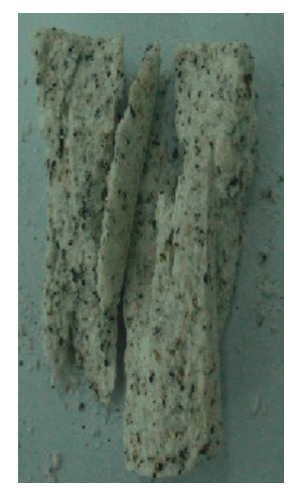

(f)
FIgURE 7: Failure modes of granite under uniaxial compression tests at different temperatures. (a) $25^{\circ} \mathrm{C}$, (b) $200^{\circ} \mathrm{C}$, (c) $400^{\circ} \mathrm{C}$, (d) $600^{\circ} \mathrm{C}$, (e) $800^{\circ} \mathrm{C}$, and (f) $1000^{\circ} \mathrm{C}$.

4.2. Thermal Damage $\left(D_{T}\right)$ Caused by Temperature. Many researchers found that rock elastic modulus is the function of temperature [35], so it may be defined as $D_{T}$ to describe the temperature effect on rock mechanical performances. Assuming $D_{T}$ is zero at $25^{\circ} \mathrm{C}$ and then at the temperature of $T, D_{T}$ can be defined as follows:

$$
D_{T}=1-\frac{E_{T}}{E_{0}},
$$

where $E_{0}$ is the elastic modulus of granite at $25^{\circ} \mathrm{C}$ and $E_{T}$ is the elastic modulus at the temperature of $T$. Table 1 gives the 


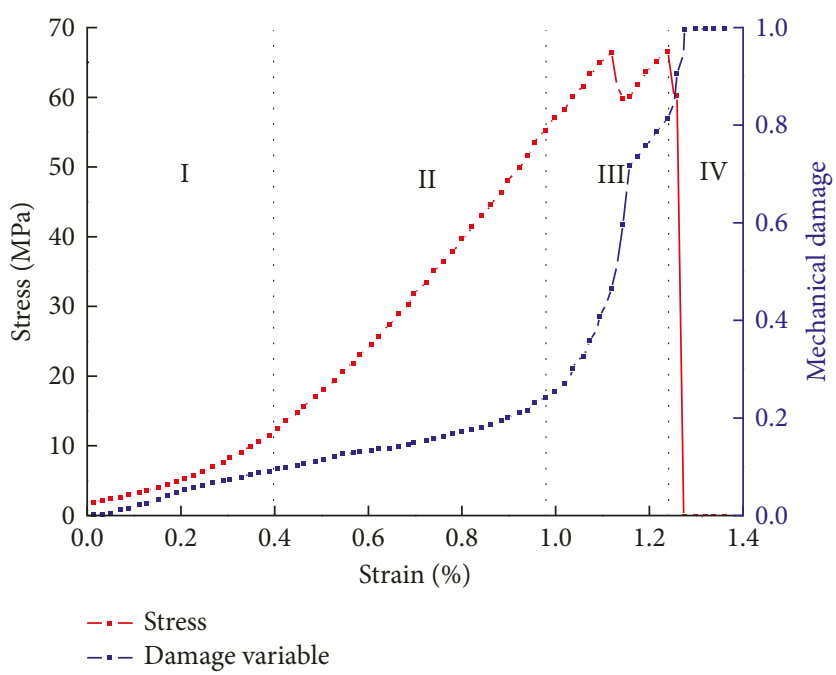

Figure 8: Mechanical damage and the stress-strain curve under uniaxial compression test at room temperature.

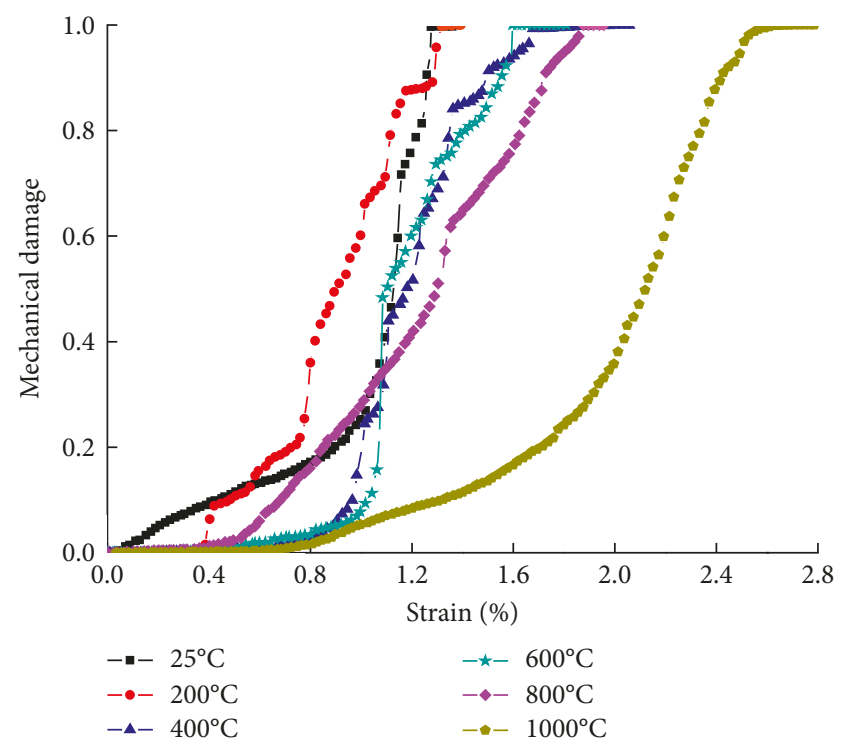

Figure 9: Mechanical damage with strain at various temperatures.

TABLE 1: Mechanical and damage values of granite at different temperatures.

\begin{tabular}{lcccccc}
\hline $\begin{array}{l}\text { Temperature } \\
\left({ }^{\circ} \mathrm{C}\right)\end{array}$ & $\begin{array}{c}\text { Peak stress } \\
(\mathrm{MPa})\end{array}$ & $\begin{array}{c}\text { Peak strain } \\
(\%)\end{array}$ & $\begin{array}{c}\text { Accumulated AE counts } \\
\left(10^{5}\right)\end{array}$ & $\begin{array}{c}\text { Elastic modulus } \\
(\mathrm{GPa})\end{array}$ & $\begin{array}{c}\text { Thermal } \\
\text { damage }\end{array}$ & $\begin{array}{c}\text { Maximum damage } \\
\text { evolution rate }\end{array}$ \\
\hline 25 & 79.443 & 1.239 & 22.906 & 7.843 & 0 & 1417.207 \\
200 & 66.278 & 1.065 & 14.777 & 7.084 & 0.097 & 554.663 \\
400 & 55.781 & 0.983 & 5.609 & 4.981 & 0.365 & 492.039 \\
600 & 30.161 & 1.062 & 1.354 & 3.248 & 0.586 & 483.524 \\
800 & 31.623 & 1.288 & 25.341 & 1.890 & 0.759 & 170.652 \\
1000 & 24.825 & 1.985 & 10.755 & 1.582 & 0.798 & 57.398 \\
\hline
\end{tabular}




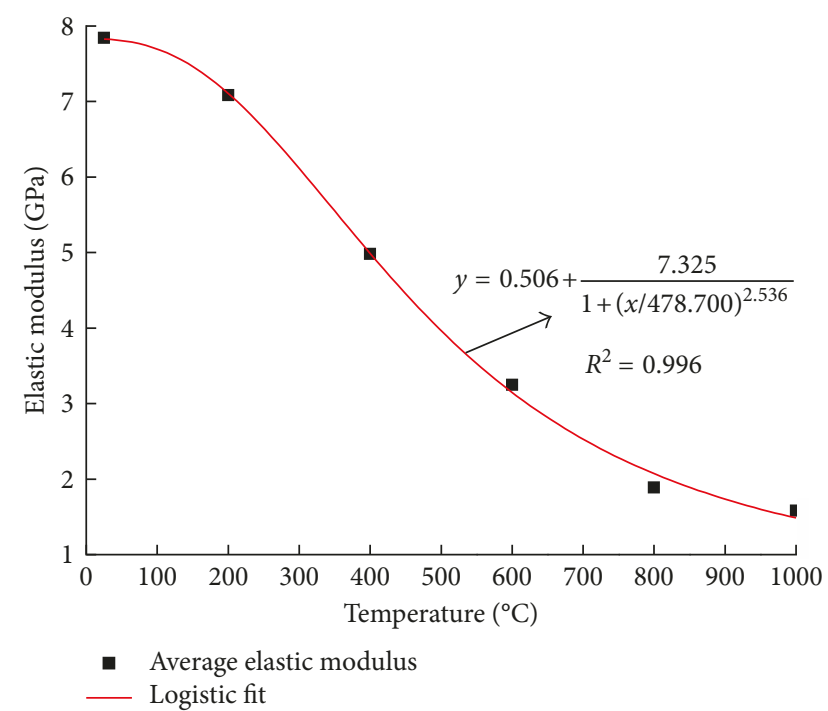

Figure 10: Average elastic modulus with temperature.

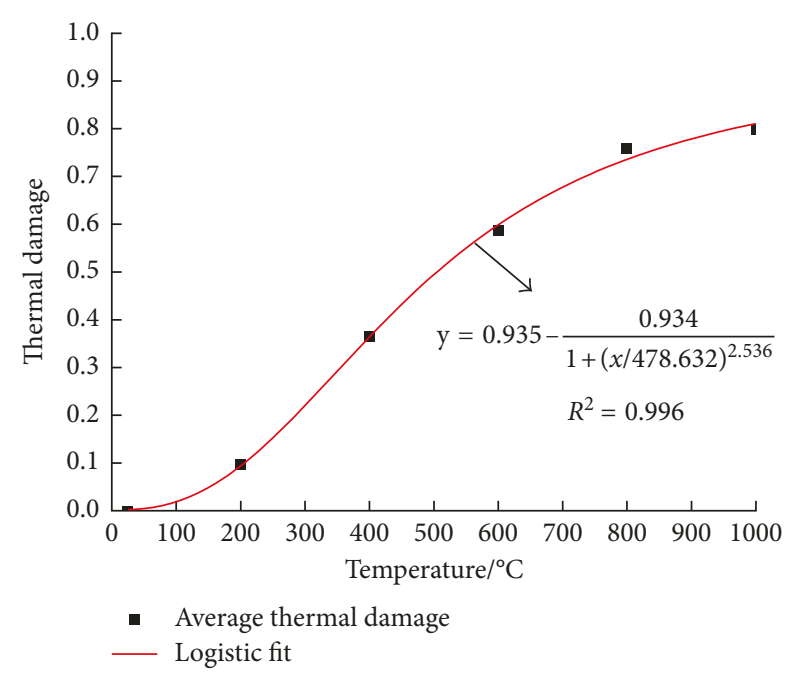

Figure 11: Average thermal damage with temperature.

average values of elastic modulus and $D_{T}$ at different temperatures.

The average elastic modulus shows logistic decline with the rise of temperature (Figure 10), and the fitting function is

$$
y=0.506+\frac{7.325}{1+(x 478.700)^{2.536}}, \quad R^{2}=0.996
$$

While the average thermal damage shows logistic increase with the rise of temperature (Figure 11), the fitting function is

$$
y=0.935-\frac{0.934}{1+(x 478.632)^{2.536}}, \quad R^{2}=0.996 .
$$

The high temperature leads to the increase of rock molecules thermal motion, and the thermal expansion of various minerals across the grain boundary is not coordinated, resulting in a large number of microcracks. With

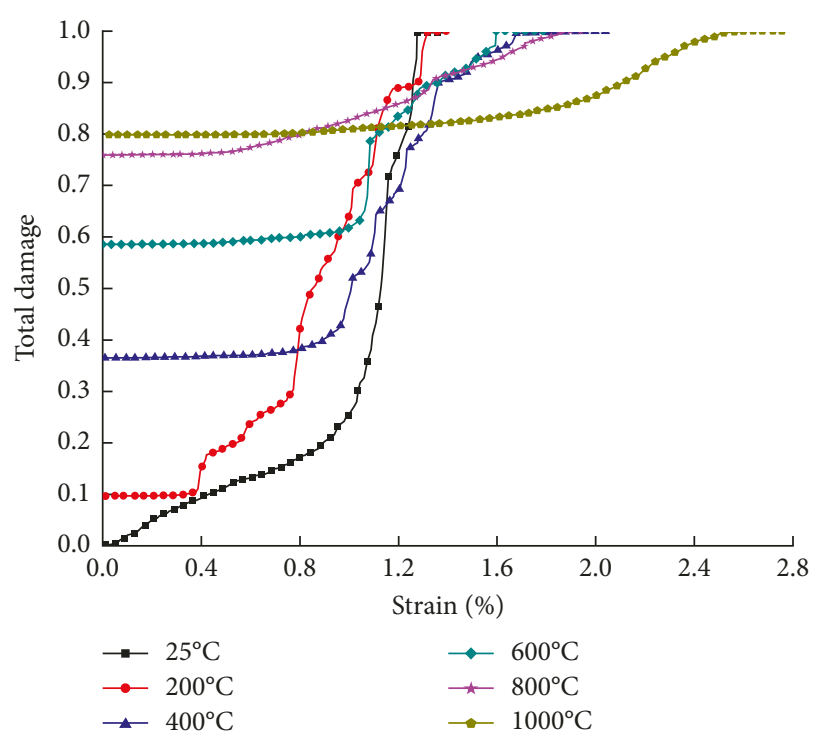

FIgURE 12: Total damage with strain.

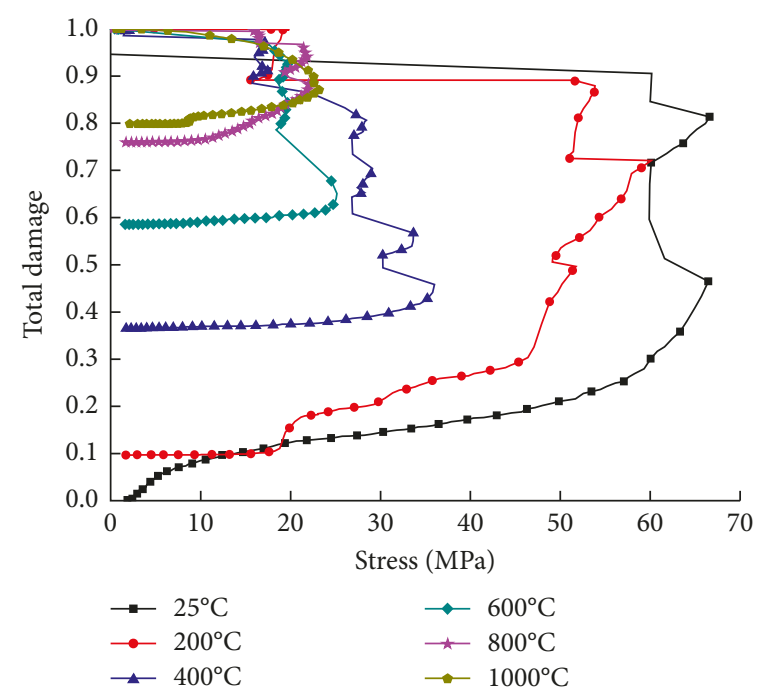

FIgURE 13: Total damage with stress.

the increase of temperature, these microcracks are expanded and penetrated, leading to the deterioration of rock mechanical properties.

4.3. Total Damage (D) Caused by Thermomechanical Coupling. Under the action of temperature and loading, the rock shows different damage characteristics. The total damage of the loaded rock at high temperature conditions can be derived from Lemaitre's strain equivalence principle [36], and the total damage $D$ can be calculated by the following equation [37]:

$$
D=D_{T}+D_{M}-D_{T} D_{M}
$$

According to (9), the curves of rock total damage with axial strain and axial stress at various temperatures are shown in Figures 12 and 13. The initial $D$ is the corresponding 


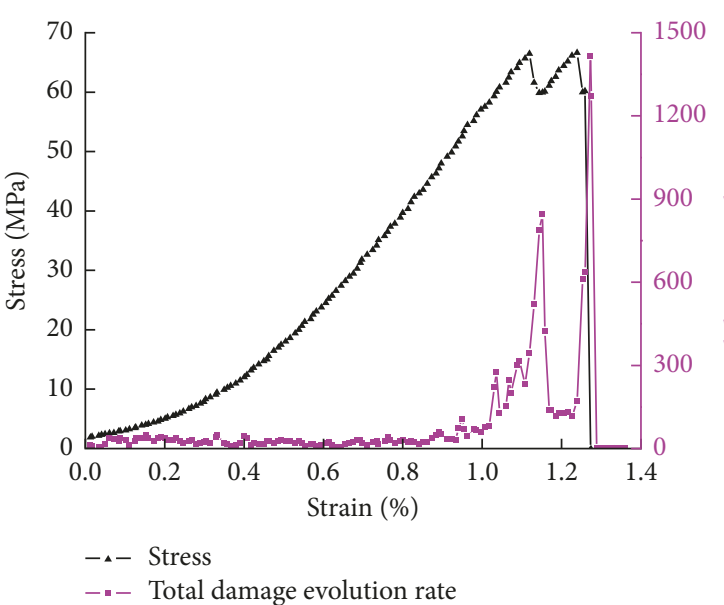

(a)

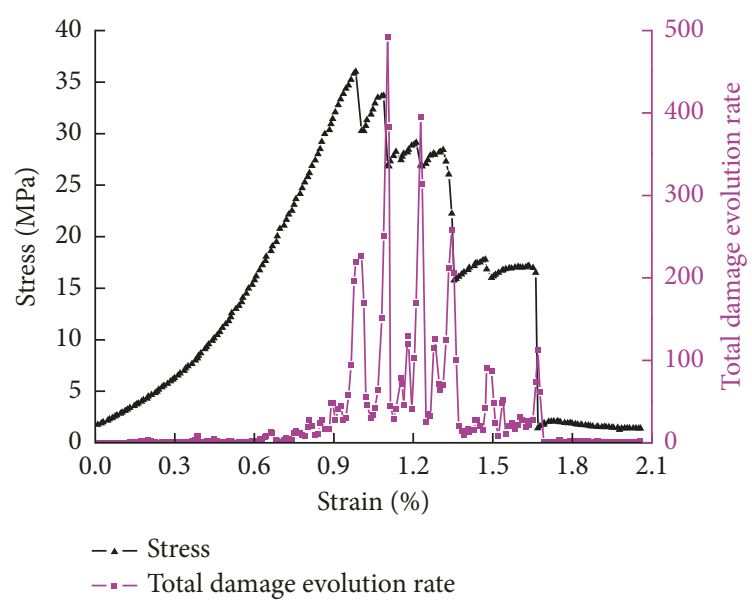

(c)

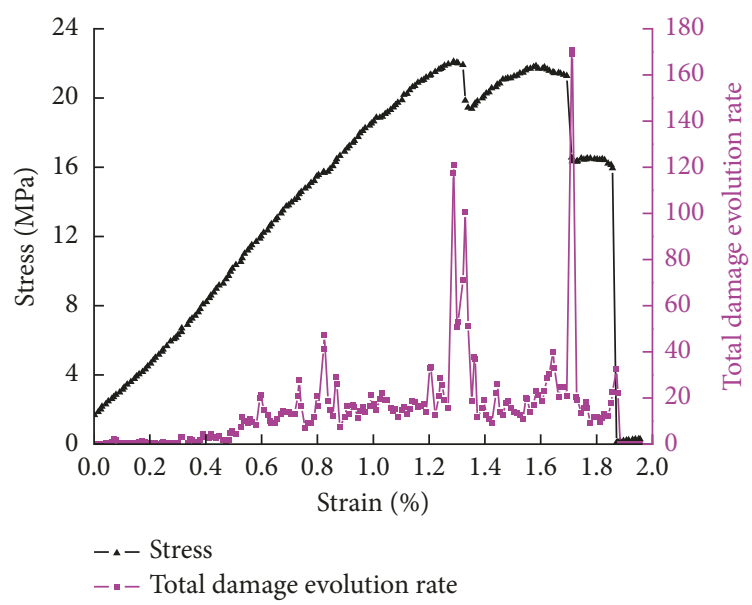

(e)

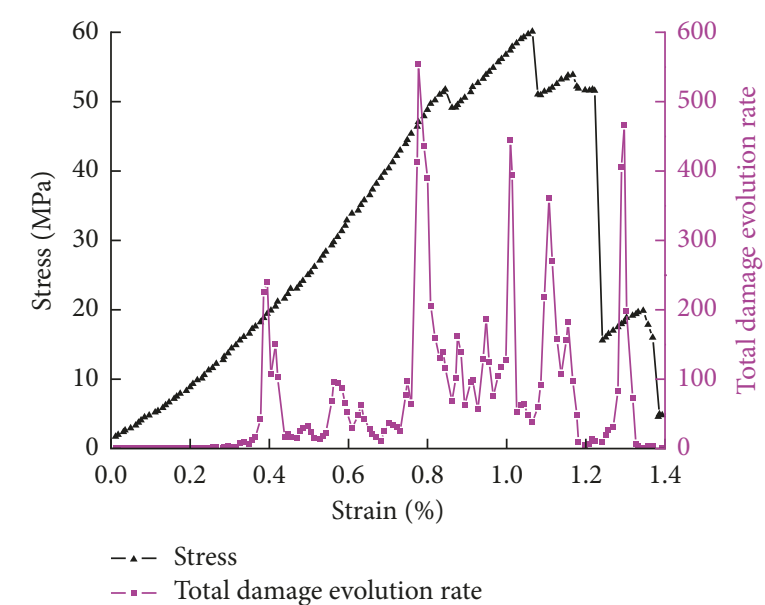

(b)

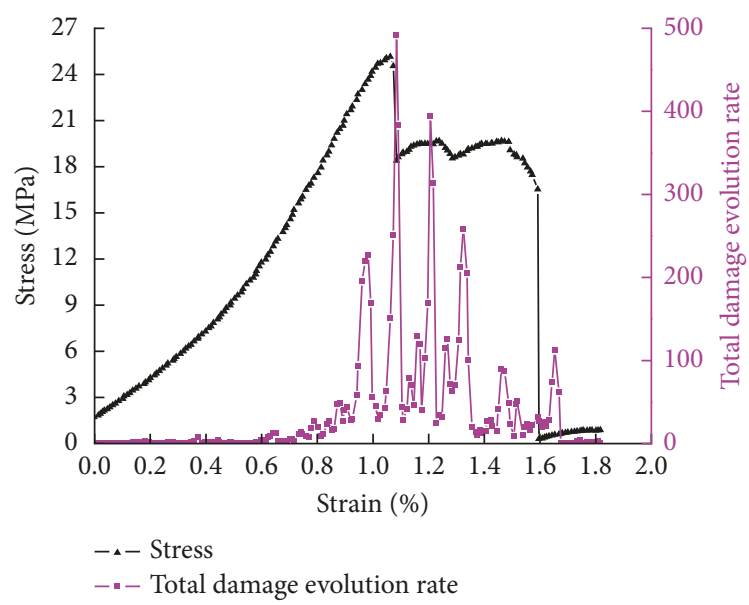

(d)

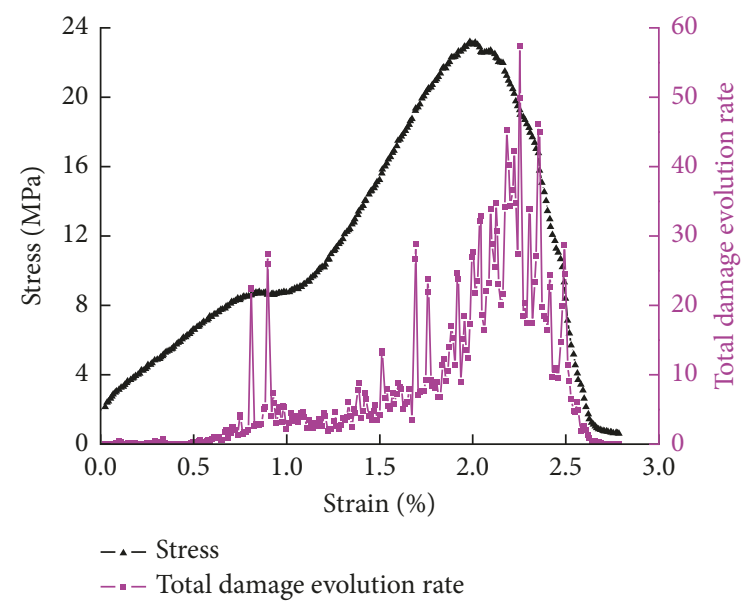

(f)

Figure 14: Total damage evolution rate at various temperatures. (a) $25^{\circ} \mathrm{C}$, (b) $200^{\circ} \mathrm{C}$, (c) $400^{\circ} \mathrm{C}$, (d) $600^{\circ} \mathrm{C}$, (e) $800^{\circ} \mathrm{C}$, and (f) $1000^{\circ} \mathrm{C}$.

$D_{T}$ when strain and stress equal to zero, and then $D$ increases with the rise of strain, which can reflect the whole rock failure process of microcracks compaction, initiation, expansion, and destruction.
With the rise of temperature, the growth trend of rock total damage slows down. At the same damage value, the corresponding strain becomes larger. It means that the rise of temperature causes the intensification of 


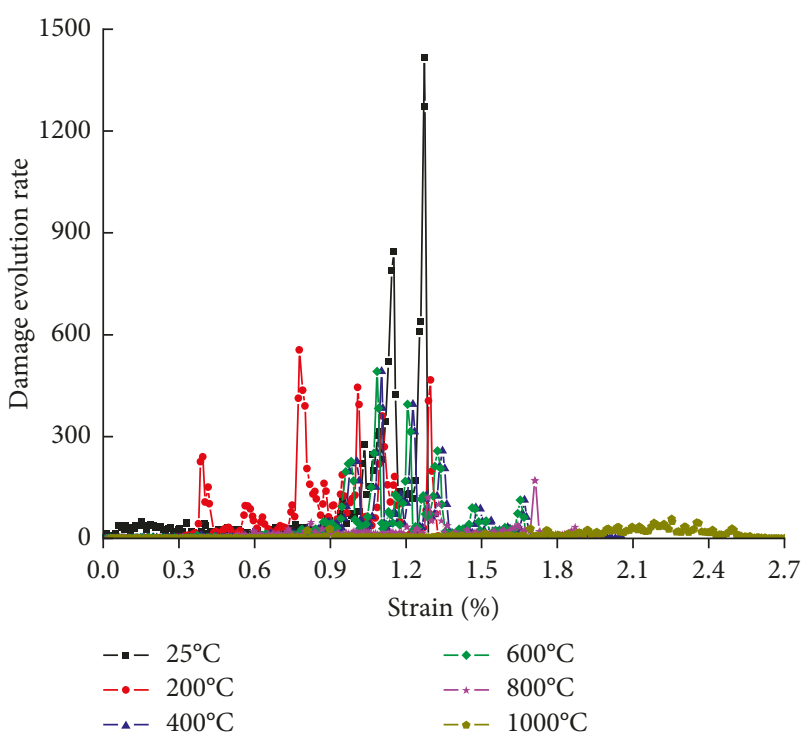

FIgURE 15: Damage evolution rate at various temperatures.

dislocation movement between rock particles, leading to the weakness of rock strain recovery ability, and thus, the plasticity is enhanced. Figure 13 indicates that $D$ is not only related to the stress state, but also related to the temperature.

By differentiating (9) to axial strain, the damage evolution rate of rock can be obtained, and the curves are shown in Figure 14.

As the accumulated AE counts, the curve of the rock damage evolution rate also has a good correspondence with stress-strain curves. The area surrounded by the damage evolution rate curve is just the value of rock mechanical damage.

The maximum damage evolution rate of rock shows logistic decline with the rise of temperature (Figures 15 and $16)$; the logistic fitting function is

$$
y=-3969.859+\frac{15428.98}{1+(x 0.0611)^{0.104}}, \quad R^{2}=0.875 .
$$

It needs to be emphasized here that the rock $\mathrm{AE}$ events during uniaxial loading are not increased monotonically but show the law of "interval burst" and "relatively calm," that is, after each burst of $\mathrm{AE}$ events, the AE number is minimal for the next period of time, and this phenomenon is not just before peak stress but in the whole compression test. The "interval burst" and "relatively calm" phenomena can be explained from the energy point of view. When the rock is subjected to external loading, the energy inside the rock will be released, resulting the number of AE events to rise sharply; then the rock will be in the state of "pressure relief" after energy release, and $\mathrm{AE}$ events will drop down and show "calm." With the increase of loading, the internal energy will transfer from the "pressure relief" state to the "balanced" state. When loading is further increased, the rock in the "balanced" state will once again release energy, leading to the number of $\mathrm{AE}$ ring counts to increase dramatically. It should be noted that the AE "calm" state

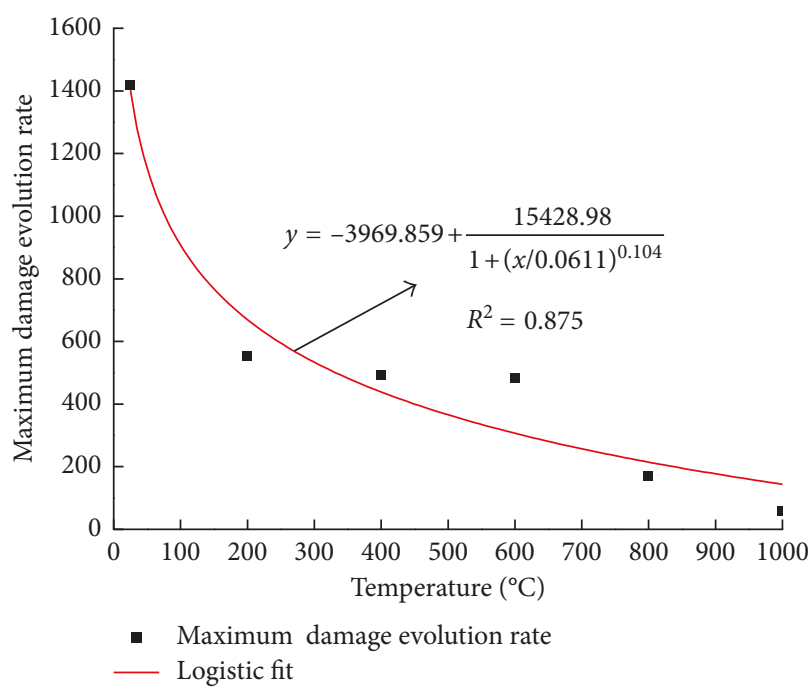

Figure 16: Maximum damage evolution rate with temperature.

explained here is not an absolute sense of zero AE event, but a relative concept.

\section{Conclusions}

Through the uniaxial compression $\mathrm{AE}$ test of granite at different high temperatures $\left(25^{\circ} \mathrm{C}, 200^{\circ} \mathrm{C}, 400^{\circ} \mathrm{C}, 600^{\circ} \mathrm{C}\right.$, $800^{\circ} \mathrm{C}$, and $1000^{\circ} \mathrm{C}$ ), the rock mechanical properties, $\mathrm{AE}$ characteristics, failure modes, and damage evolution curves were all analyzed. The thermal damage is defined by the elastic modulus, the mechanical damage is obtained by $\mathrm{AE}$ ring count rate, and the total damage is derived by Lemaitre's strain equivalence principle. The law of rock damage evolution is corresponding to experimental phenomena at different temperatures, which verifies that it is reasonable and feasible to establish a rock damage model by using $\mathrm{AE}$ technology. The conclusions are as follows:

(1) The rock stress-strain curve can be divided into four stages of compaction, elasticity, yield, and failure. The rise of temperature leads to the weakness of rock brittleness and the enhancement of rock plasticity.

(2) The AE ring count rate of rock shows the law of "interval burst" and "relatively calm," which can be explained from the energy point of view.

(3) From $25^{\circ} \mathrm{C}$ to $1000^{\circ} \mathrm{C}$, the rock failure mode changes from single splitting failure to multisplitting failure, and then to incomplete shear failure, ideal shear failure, and double shear failure, until complete integral failure.

(4) The thermal damage shows that logistic increases with the rise of temperature. The mechanical damage curve can be divided into initial damage stage, stable development stage, accelerated development stage, and destructive stage, which shows correspondence with the stress-strain curve.

(5) The total damage increases with the rise of strain, which can reflect the whole rock failure process of 
microcracks compaction, initiation, expansion, and destruction. With the rise of temperature, the growth trend of total damage slows down and the maximum damage evolution rate shows logistic decline.
Abbreviations
ISRM: International society of rock mechanics
AE: Acoustic emission
$D_{M}: \quad$ Mechanical damage
$D_{T}$ : Thermal damage
D: Total damage.

\section{Conflicts of Interest}

The authors declare that they have no conflicts of interest.

\section{Acknowledgments}

This work had been financially supported by the National Natural Science Foundation of China (nos. 11202108 and 51604260), the Opening Fund of State Key Laboratory for Geomechanics and Deep Underground Engineering of China University of Mining and Technology (no. SKLGDUEK1204), and the Natural Science Foundation of Jiangsu Province of China (no. BK20160416).

\section{References}

[1] Y. L. Chen, J. Ni, W. Shao, and R. Azzam, "Experimental study on the influence of temperature on the mechanical properties of granite under uni-axial compression and fatigue loading," International Journal of Rock Mechanics and Mining Sciences, vol. 56, pp. 62-66, 2012.

[2] V. Brotóns, R. Tomás, S. Ivorra, and J. C. Alarcón, “Temperature influence on the physical and mechanical properties of a porous rock: San Julian's calcarenite," Engineering Geology, vol. 167, pp. 117-127, 2013.

[3] A. Ozguven and Y. Ozcelik, "Effects of high temperature on physico-mechanical properties of Turkish natural building stones," Engineering Geology, vol. 183, pp. 127-136, 2014.

[4] S. S. Shao, P. G. Ranjith, P. L. P. Wasantha, and B. K. Chen, "Experimental and numerical studies on the mechanical behavior of Australian Strathbogie granite at high temperatures: an application to geothermal energy," Geothermics, vol. 54, pp. 96-108, 2015.

[5] S. Liu and J. Y. Xu, "An experimental study on the physicomechanical properties of two post-high-temperature rocks," Engineering Geology, vol. 185, pp. 63-70, 2015.

[6] R. Tiskatine, A. Eddemani, L. Gourdo et al., "Experimental evaluation of thermo-mechanical performances of candidate rocks for use in high temperature thermal storage," Applied Energy, vol. 171, pp. 243-255, 2016.

[7] Q. Sun, C. Lü, L. W. Cao, W. C. Li, J. S. Geng, and W. Q. Zhang, "Thermal properties of sandstone after treatment at high temperature," International Journal of Rock Mechanics and Mining Sciences, vol. 85, pp. 60-66, 2016.

[8] X. F. Liu, S. Y. Yuan, Y. Sieffert, S. Fityus, and O. Buzzi, "Changes in mineralogy, microstructure, compressive strength and intrinsic permeability of two sedimentary rocks subjected to high-temperature heating," Rock Mechanics and Rock Engineering, vol. 49, no. 8, pp. 2985-2998, 2016.
[9] X. L. Xu and Z. Z. Zhang, "Fractal characteristics of rock fracture surface under triaxial compression after high temperature," Advances in Materials Science and Engineering, vol. 2016, Article ID 2181438, 10 pages, 2016.

[10] L. Chen, J. Wang, Z. H. Zong et al., "A new rock mass classification system QHLW for high-level radioactive waste disposal," Engineering Geology, vol. 190, pp. 33-51, 2015.

[11] E. D. Korkmaz, U. Serpen, and A. Satman, "Geothermal boom in Turkey: growth in identified capacities and potentials," Renewable Energy, vol. 68, pp. 314-325, 2014.

[12] P. Vázquez, V. Shushakova, and M. Gómez-Heras, "Influence of mineralogy on granite decay induced by temperature increase: experimental observations and stress simulation," Engineering Geology, vol. 189, pp. 58-67, 2015.

[13] B. Y. Zhang, J. H. Zhang, and G. L. Sun, "Deformation and shear strength of rock fill materials composed of soft siltstones subjected to stress, cyclical drying/wetting and temperature variation," Engineering Geology, vol. 190, pp. 87-97, 2015.

[14] S. Mccabe, B. J. Smith, and P. A. Warke, "Exploitation of inherited weakness in fire-damaged building sandstone: the 'fatiguing' of 'shocked' stone," Engineering Geology, vol. 115, no. 3-4, pp. 217-225, 2010.

[15] C. Kuenzer and G. B. Stracher, "Geomorphology of coal seam fires," Geomorphology, vol. 138, no. 1, pp. 209-222, 2012.

[16] Y. Chen, "Application of acoustic emission techniques to rock mechanics research," Acta Geophysica Sinica, vol. 20, no. 4, pp. 312-322, 1977.

[17] M. D. Read, M. R. Ayling, P. G. Meredith, and S. A. F. Murrell, "Microcracking during triaxial deformation of porous rocks monitored by changes in rock physical properties, II. Pore volumometry and acoustic emission measurements on watersaturated rocks," Tectonophysics, vol. 245, no. 3-4, pp. 223235, 1995.

[18] V. Rudajev, J. Vilhelm, and T. Lokajicek, "Laboratory studies of acoustic emission prior to uniaxial compressive rock failure," International Journal of Rock Mechanics and Mining Sciences, vol. 37, no. 4, pp. 699-704, 2000.

[19] L. H. Chen, W. C. Chen, Y. C. Chen, L. Benyamin, and A. J. Li, "Investigation of hydraulic fracture propagation using a postpeak control system coupled with acoustic emission," Rock Mechanics and Rock Engineering, vol. 48, no. 3, pp. 1233-1248, 2015.

[20] P. Ganne, A. Vervoort, and M. Wevess, "Quantification of pre-peak brittle damage: correlation between acoustic emission and observed micro-fracturing," International Journal of Rock Mechanics and Mining Sciences, vol. 48, no. 5, pp. 720-729, 2007.

[21] H. Alkan, Y. Cinar, and G. Pusch, "Rock salt dilatancy boundary from combined acoustic emission and triaxial compression tests," International Journal of Rock Mechanics and Mining Sciences, vol. 44, no. 1, pp. 108-119, 2007.

[22] M. C. He, J. L. Miao, and J. L. Feng, "Rock burst process of limestone and its acoustic emission characteristics under truetriaxial unloading conditions," International Journal of Rock Mechanics and Mining Sciences, vol. 47, no. 2, pp. 286-298, 2010.

[23] J. Gasc, A. Schubne, F. Brunet, S. Guillon, H. Mueller, and C. Lathe, "Simultaneous acoustic emissions monitoring and synchrotron X-ray diffraction at high pressure and temperature: calibration and application to serpentinite dehydration," Physics of the Earth and Planetary Interiors, vol. 189, no. 3-4, pp. 121-133, 2011.

[24] A. Chmel and I. Shcherbakov, "A comparative acoustic emission study of compression and impact fracture in 
granite," International Journal of Rock Mechanics and Mining Sciences, vol. 64, pp. 56-59, 2013.

[25] C. D. Zhang, W. G. Liang, Z. G. Li, S. G. Xu, and Y. S. Zhao, "Observations of acoustic emission of three salt rocks under uniaxial compression," International Journal of Rock Mechanics and Mining Sciences, vol. 77, pp. 19-26, 2015.

[26] Z. Z. Zhang, X. L. Xu, Q. P. Sun, and Y. Dong, "Effect of thermal treatment on fractals in acoustic emission of rock material," Advances in Materials Science and Engineering, vol. 2016, Article ID 6309856, 9 pages, 2016.

[27] Q. L. Guo, G. Rong, M. D. Yao, L. Cheng, J. Yang, and J. Peng, "Experimental study on acoustic emission behaviors and mechanical properties of thermal damaged marbles," China Journal of Rock Mechanics and Engineering, vol. 34, no. 12, pp. 2388-2400, 2015.

[28] M. Caia, H. Moriokab, P. K. Kaisera et al., "Back-analysis of rock mass strength parameters using AE monitoring data," International Journal of Rock Mechanics and Mining Sciences, vol. 44, no. 4, pp. 538-549, 2007.

[29] S. Kramadibrata, G. M. Simangunsong, K. Matsui, and H. Shimada, "Role of acoustic emission for solving rock engineering problems in Indonesian underground mining," Rock Mechanics and Rock Engineering, vol. 44, no. 3, pp. 281-289, 2011.

[30] C. E. Fairhurst and J. A. Hudson, "Draft ISRM suggested method for the complete stress-strain curve for the intact rock in uniaxial compression," International Journal of Rock Mechanics and Mining Sciences, vol. 36, no. 3, pp. 276-289, 1999.

[31] B. Kong, E. Y. Wang, Z. H. Li, X. R. Wang, Y. Niu, and X. G. Kong, "Acoustic emission signals frequency-amplitude characteristics of sandstone after thermal treated under uniaxial compression," Journal of Applied Geophysics, vol. 136, pp. 190-197, 2017.

[32] X. L. Xu, F. Gao, Z. Z. Zhang, and C.-H. Zhang, "Energy and structural effects of granite after high temperature," Chinese Journal of Geotechnical Engineering, vol. 36, no. 5, pp. 961968, 2014

[33] G. X. Chen and Y. M. Zhang, Mineral Thermal Analysis Spectrum Manual of Powder Diffraction Analysis of Phase Change, Sichuan Science and Technology Press, Chengdu, China, 1989.

[34] T. H. Yang, X. L. Tu, and B. Yu, "A micro-mechanical model for simulating the coupling of fracture and flow of rock," Acta Mechanica Solida Sinica, vol. 26, no. 3, pp. 333-337, 2005.

[35] W. Zhang, Q. Sun, L. Cao, and B. Wang, "Thermal damage on claystone after exposure to different high temperatures: a review," Geotechnical Testing Journal, vol. 40, no. 2, pp. 351-360, 2017.

[36] J. Lemaitre, A Course on Damage Mechanics, Springer-Verlag, Berlin, Heidelberg, Germany, 1996.

[37] H. M. Zhang and G. S. Yang, "Research on damage model of rock under coupling action of freeze-thaw and load," China Journal of Rock Mechanics and Engineering, vol. 29, no. 3, pp. 471-476, 2010. 


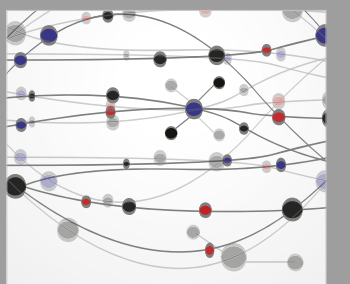

The Scientific World Journal
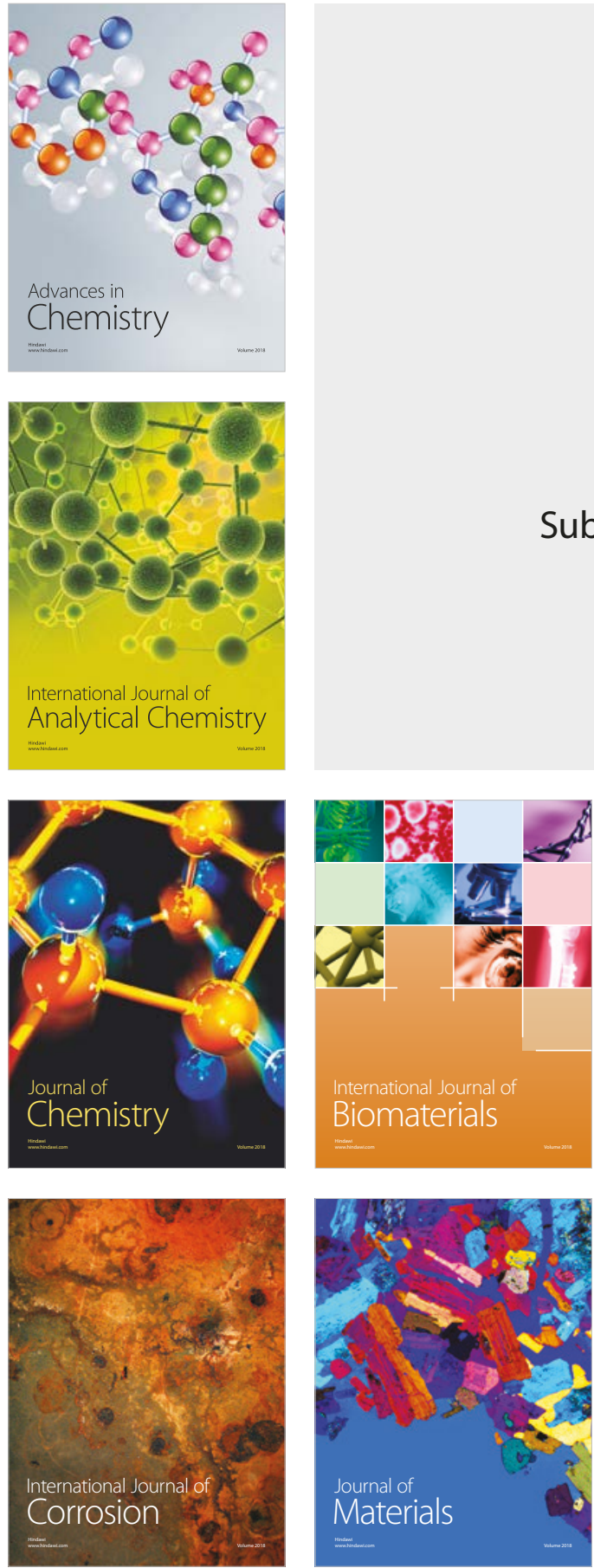

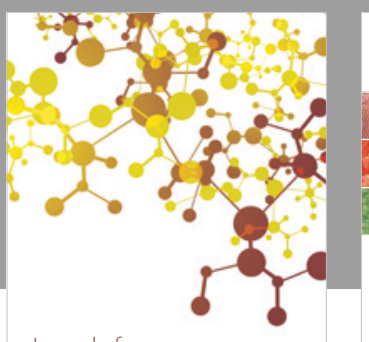

Journal of

Applied Chemistry
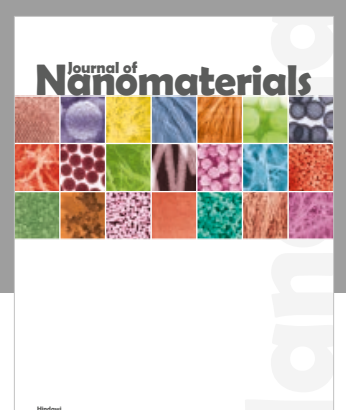

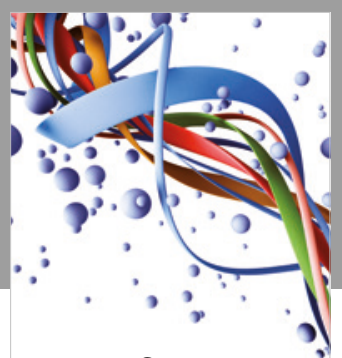

Scientifica

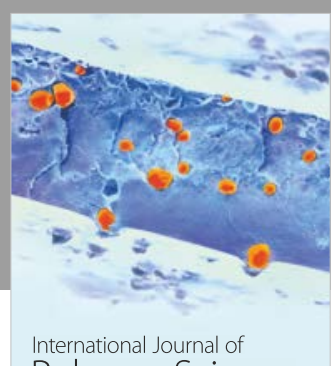

Polymer Science

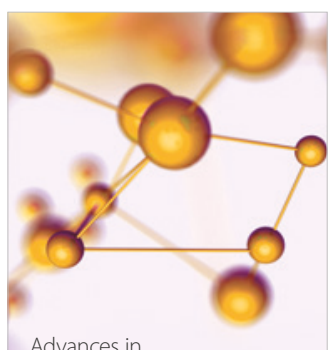

Physical Chemistry
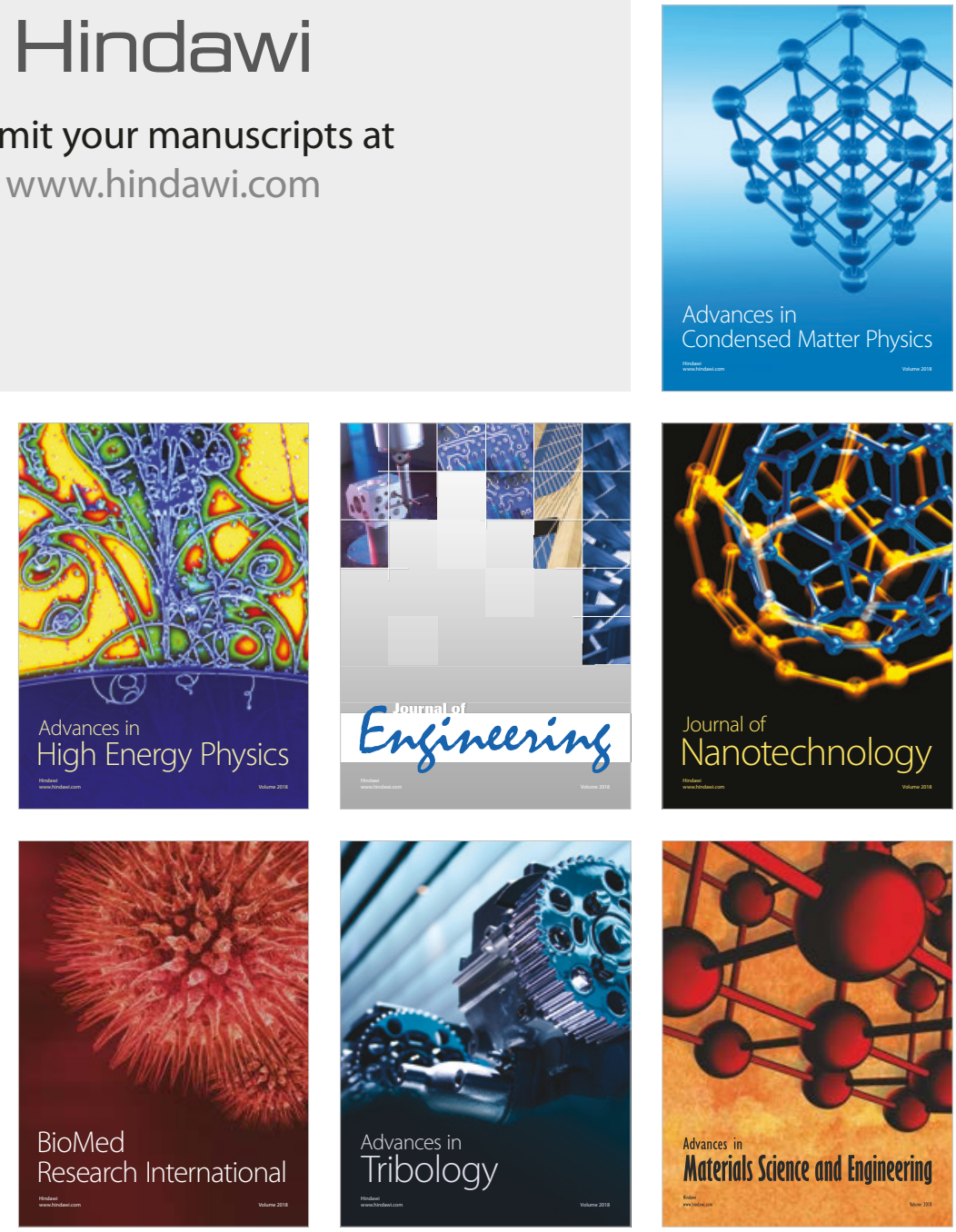